\title{
CRONOLOGÍA Y COYUNTURAS DE LOS MOVIMIENTOS SOCIALES CASTELLANOS, SIGLOS XVI Y XVII
}

\author{
Pedro Luis Lorenzo Cadarso*
}

\begin{abstract}
RESUMEN: En este trabajo se reconstruye la relación existente entre los diferentes tipos de movimientos sociales y los factores sociales, económicos, culturales y políticos que los condicionan directa o indirectamente. Todo ello con el fin de fijar una periodización general de la conflictividad social castellana en los siglos XVI y XVII. Confluyen en él, por tanto, un estudio de cronología bistórica con otro de contenidos más teóricos, referido a la problemática de la causalidad en el conflicto social.

ABSTRACT: In this work we deal with the different kinds of social movements and there social, economic, cultural and political causes whixh have influenced thend. Our wain purpore is to rettle the periods of the social confict in Castilla desing the XVI and XVII centuries: Therefore, we include a study of historial cbronology and a eway of more theoretical content related to the causality of the social conflicts.
\end{abstract}

\section{Primera fase: $1521-1540$}

Los veinte años que siguen al fracaso de la revolución comunera fueron, sin duda ninguna, los más pacíficos de toda la historia castellana hasta 1700. Parece obvio pensar que la represión y el propio desánimo de los sectores más impli-

* Doctor en Historia. Profesor del Departamento de Historia, Area de Ciencias y Técnicas Historiográficas, de la Universidad de Extremadura. 
cados en la revolución estuvieron entre las principales causas de la calma social; sobre todo si tenemos en cuenta que buena parte de las tensiones que confluyeron en las Comunidades son las mismas que provocarán los conflictos de los dos siglos siguientes: los movimientos antiseñoriales y antioligárquicos; el malestar por la vulneración de derechos tradicionales, los deseos de algunos sectores del patriciado urbano -burgueses y profesiones liberales- por ocupar un papel más destacado en la estructura de poder; o las mismas críticas al aumento de la presión fiscal.

La represión, combinada con el desánimo, puede explicar, al menos en los primeros años, que las tensiones se mantuviesen temporalmente ocultas, sobre todo entre los sectores más castigados por ella, los grupos burgueses y las comunidades de señorío. Sin embargo, esto no es suficiente.

Existen, en primer lugar, una serie de factores económicos que propiciaron la disminución de los conflictos: la coyuntura económica agraria, claramente expansiva; el desarrollo urbano gracias al floreciente negocio de la exportación lanera, el mercado americano y la producción manufacturera; y el crecimiento demográfico, perfectamente constatado en todos los ámbitos de población, tanto rurales como urbanos. Estamos, pese a típicas fluctuaciones demográficas y productivas, en una coyuntura expansiva en la que aumenta la riqueza -probablemente también el bienestar- y con ella amplios sectores sociales poseen unas expectativas claramente optimistas.

Socialmente es evidente que los sectores burgueses de la sociedad son cada vez no sólo más numerosos, sino también más ricos y con unas expectativas de poder político y ascenso social inmejorables. Las grandes aventuras financieras se ven respaldadas por un comercio exterior en expansión: la demanda flamenca de lana y las remesas de plata americana no dejan de crecer. Por otro lado, las Universidades, con un crecimiento importante de la matrícula, significan un trampolín inmejorable para encaramarse en un Estado absoluto en construcción $y$, por lo tanto, con una creciente necesidad de cuadros bien formados intelectualmente -el problema de la monopolización de los Colegios Mayores por la nobleza es posterior-.

La aristocracia nobiliaria, contra lo que ella misma había esperado, no obtiene del emperador las recompensas que necesitaba para reajustar su nivel de ingresos y su estructura de poder jurisdiccional ${ }^{1}$. Es más, la Corona dio sobradas muestras de no estar dispuesta a apoyar a la alta nobleza, algo gravísimo dado el nivel de inflación existente y la actitud hostil que habían manifestado las comunidades de señorío durante la revolución ${ }^{2}$. Las dificultades de los señores para aumentar sus ingresos, que les llevará a actuar de forma muy imprudente y agre-

1. En esto la unanimidad entre los trabajos más recientes es total. Vid. PEREZ, J. 1977 y HALICZER, S. 1987, pp. 259-288.

2. Vid. GUTIÉRREZ NIETO, J.A. 1973. 
siva en sus dominios y los problemas para ejercer como grupo dirigente en la Corte, serán factores básicos a la hora de explicar la oleada de movilizaciones antiseñoriales que se desencadenará en las décadas centrales del siglo.

En cuanto a los factores políticos e institucionales, aparte de las secuelas que pudo dejar el fracaso comunero a corto plazo, el hecho fundamental del periodo fue una profunda reforma del sistema judicial castellano, algo que tendría enorme trascendencia en toda la evolución posterior de los movimientos sociales castellanos. La reforma tuvo dos pilares básicos: la no injerencia de la Corona en los pleitos que se seguían contra la nobleza señorial, lo cual prestigiará a las instituciones judiciales y reavivará a medio plazo las esperanzas populares en poder defender sus derechos por los cauces de la legalidad; y, en segundo lugar, una reforma institucional tendente a reforzar los poderes jurisdiccionales de las Chancillerías y creando otros tribunales superiores que faciliten, haciéndolos más accesibles, el despliegue territorial del sistema judicial real, como será el caso de las Reales Audiencias de Galicia, Sevilla y Canarias. El cambio de personal en las Chancillerías y las mayores competencias que asume a costa del Consejo de Castilla ${ }^{3}$, las convertirán en tribunales rigurosos y con alta capacitación técnica ${ }^{4}$.

La actividad judicial de las Chancillerías tendrá una importancia crucial en el fracaso de los intentos señoriales de aumentar sus ingresos y sus prerrogativas jurisdiccionales en el XVI, e incluso pondrá en peligro un alto número de apropiaciones señoriales realizadas mucho antes, algunas en el reinado de Enrique II, pero muy especialmente las que se llevaron a cabo durante el de Enrique IV. Las sentencias antiseñoriales serán la norma, lo cual, como cabía esperar, provocó una segunda reforma del sistema judicial en 1598, creándose la Sala de Mil Quinientas -o Sala de Justicia- en el Consejo de Castilla, convirtiéndola en un tribunal ordinario que conocía en apelación las sentencias de las Chancillerías. De este modo se consiguió anular la ejecución de las beligerantes sentencias de las Chancillerías, convirtiéndose en un balón de oxígeno para la nobleza señorial, aunque fuese a costa de desprestigiar todo el sistema judicial entre el pueblo.

La retorma tiscal emprendida por Carlos I, muy condicionada siempre por los dramáticos sucesos de 1518-1521, renunció, de forma ya definitiva, al arrendamiento de los impuestos a recaudadores particulares, práctica muy odiada por el

3. Para 1539 había ya un elevado número de pleitos judiciales apelados en segunda suplicación ante el Consejo de Castilla, la Corona respondió con una serie de medidas tendentes a agilizar los trámites judiciales, evitando así que las apelaciones al Consejo se instrumentalizasen por los condenados en la Chancillerías, que retrasaban con la apelación la ejecución de las sentencias. En 1539 se impidió que se apelasen pleitos de poca importancia; en 1541 se redujeron de 5 a 4 el número de oidores necesarios para dictar sentencia y en 1543 se habilitó al Consejo para denegar el derecho a la segunda suplicación unilateralmente.

4. Un análisis introductorio a este proceso en HALICZER, S. 1987, pp. 269-272 
pueblo castellano ${ }^{5}$, optando por los encabezamientos, que permitirán que los concejos gestionen la recaudación y realizar una negociación individualizada de la carga fiscal de cada localidad, adaptándola a la situación económica por la que atravesase en cada momento. Se evitaron de este modo muchas tensiones sociales, en parte porque se renunciaba a un cobro expeditivo de los impuestos, pero sobre todo porque la gestión municipal de las actividades recaudatorias imbricaba a las élites locales en todo el entramado fiscal -incluso, la recaudación les servía como un arma política más con la que defender sus intereses o perseguir a los grupos enemigos-, las cuales terminaron por ser consideradas por el pueblo como las principales responsables de cualquier aumento de los impuestos o de cualquier práctica recaudatoria dura. La Corona resultaba exculpada de toda responsabilidad directa y ello evitaba que, como sucedió a menudo en el resto de Europa, las movilizaciones antifiscales tomasen un peligroso cariz antiabsolutista.Además, como es lógico, los encabezamientos significaban en periodos de expansión demográfica y económica una rebaja de la carga fiscal que en términos reales recaía sobre cada vecino.

Además, en el conjunto del reinado de Carlos I, la presión fiscal aumentará en números absolutos en torno al 50\% o 60\%, poco frente a una inflación que aumenta en más del $100 \%{ }^{6}$. La Corona, por supuesto, no acomodó el gasto a sus ingresos reales, pero todavía tenía un patrimonio público susceptible de ser enajenado, arrendado o sobre el que situar juros, de modo que a corto plazo no había problemas para acumular deuda pública; las consecuencias de esta política no tardarían en hacerse visibles. De momento, todas estas prácticas no le hacían perder a la Corona un ápice de su prestigio y su poder; al revés, eran un recurso con el que crear vínculos de dependencia hacia el Estado y hacer coincidir los intereses de la Corona con las expectativas de amplios sectores sociales.

Si bien es cierto que entre 1521 y 1540 la conflictividad social es escasa, no lo es menos que estamos en un periodo clave para poder entender las oleadas de conflictividad de las fases siguientes. Desde un punto de vista socioeconómico, la expansión del capitalismo castellano posibilitará el encumbramiento de la burguesía, primero estrictamente económico, pero que rápidamente empezará a provocar una dislocación profunda de las estructuras sociales heredadas de la Edad Media.

El Estado Absoluto, otro factor clave para entender los conflictos sociales castellanos, adquiere también en este periodo algunos de sus rasgos definitorios,

5. La labor de los recaudadores de impuestos, oficios venales o arrendados en la mayoría de los países europeos, fue una de las principales causas de las rebeliones populares. El caso más conocido es el de Francia, donde la taille en el XVII y la gabela -sobre la sal- en el XVI, cobradas por recaudadores venales provocaron sangrientas sublevaciones populares. Vid., MOUSNIER, R. 1976 y PORSHNEV, B. 1978.

6. Cfr., LARRAZ, J. 1943; NADAL, J. 1959 y VILAR, P. 1982, pp. 101-110. 
tanto a nivel institucional -se opta definitivamente por el sistema polisinodial, creándose los consejos de Estado (1521), Indias (1524) y Hacienda (1523)- como en sus estrategias fiscales -recaudación mediante encabezamientos-, de reclutamiento de funcionarios - predominio de los licenciados universitarios- y de toma de decisiones -judicialización de la política e imbricación de las élites locales en el Estado a través de las Cortes y de los concejos-. Un Estado Absoluto, en suma, no sólo respetuoso con los intereses de determinados sectores sociales, sino también con los instrumentos necesarios para lograr que éstos ligasen su porvenir al cumplimiento de los intereses económicos y políticos del Absolutismo.

\section{SEGUNDA FASE: $1540-1609$}

La calma social que vivía Castilla empezó a verse turbada por una serie de cambios económicos, sociales e institucionales que exigieron la adopción por los distintos grupos sociales de posturas agresivas.

Institucionalmente, la situación financiera de la Hacienda Real se volvió desesperada en los años treinta ${ }^{7}$, haciéndose necesario, ante el temor de provocar otra revolución comunera exigiendo un aumento de las alcabalas o los servicios, recurrir a medidas recaudatorias basadas en la enajenación del patrimonio real. Por un lado, se vendieron de forma masiva regimientos perpetuos, y esto se hizo -por primera y última vez- sin discriminar socialmente a los compradores. Gracias a ello, un buen número de Ayuntamientos cayeron en manos de la burguesía mercantil -sólo en La Rioja, esto sucedió en Alfaro, Calahorra y Logroño, los tres principales núcleos de población-, que desplazó unas veces a los viejos linajes hidalgos y otras suprimió los gobiernos asamblearios medievales. El fenómeno de las perpetuaciones no sólo se extendió a un número enorme de poblaciones, sino que significó una dislocación de las jerarquías sociales en muchas de ellas.

La resistencia de los estamentos hidalgos a compartir el papel de grupo dirigente a nivel local se sumó a los sentimientos antioligárquicos populares, dando lugar a tensiones sociales graves, aunque como el prestigio de las instituciones judiciales absolutistas era todavía grande pudieron ser canalizadas hacia los cauces de la legalidad y rara vez se produjeron tumultos violentos. El miedo a la burguesía llegó a hacerse patente en las Cortes de Castilla desde los años cuarenta, donde se llegó a exigir que los mercaderes y demás oficiales mecánicos fuesen inhabilitados para ejercer cargos públicos, pero mucho más habitualmente en los concejos, donde se introdujeron o se intentaron introducir ordenanzas prohi-

7. Cfr., DOMÍNGUEZ ORTIZ,A. 1985, pp. 151-153; y CARANDE, E. 1977, vol. II, pp. 105-134 
biendo el acceso de mercaderes y $\operatorname{conversos}^{8}$, como sucedió, por ejemplo, en Logroño en 1560:

\footnotetext{
"Que en el segundo estado, que en la concordia dice de hombres buenos, diga y sea de labradores cristianos viejos, (...) y que en este estado de labradores cristianos viejos puedan entrar y ser elegidos y elegir cualquier vecino desta ciudad con que no haya sido reconciliados ni descendientes de reconciliados por el Sto. Oficio ni quemado ni descendiente del, ni tenga oficio mecánico vil, porque estos no han de ser elegidos ni electores"”.
}

Tras la bancarrota de 1557, Felipe II comenzará a autorizar la supresión de los regimientos perpetuos en las localidades más conflictivas y entre 1560 y 1561 un buen número de ellas aprovechará para hacerlo, a pesar del enorme esfuerzo financiero que exigía. De cualquier modo, incluso en las localidades donde se consumen los regimientos continúan los conflictos. Por una lado, la situación social hace que los regimientos electivos no sean ya un instrumento con el que evitar la oligarquización; por otro, la burguesía no renuncia a sus deseos de ascender socialmente y de controlar políticamente los concejos.

Por si esto fuera poco, las necesidades financieras de la Corona le llevan a recurrir de nuevo a la venta masiva de oficios municipales entre 1580 y 1585 . Esta vez el Consejo de Hacienda será más riguroso a la hora de estudiar la condición social de los compradores; no discrimina a la burguesía, pero impide que monopolice el poder.

Las movilizaciones antioligárquicas aumentan su radicalidad a finales de siglo, fundamentalmente porque son protagonizadas por el pueblo llano -volverán a consumirse regimientos entre 1596 y 1603 , pero esta vez la Corona no lo autorizará para evitar conflictos, sino para recaudar dinero-. Los plebeyos enriquecidos en el XVI forman ya parte de la nobleza o prefieren pactar individualmente con ella -a través de vinculaciones clientelares o de los matrimonios- y no participan en los intentos de desbancarla del poder.

Otro cambio político-institucional de enorme trascendencia será el constante aumento de la presión fiscal ${ }^{10}$, sobre todo en dos momentos claves: la renegociación de las alcabalas en 1575 y la imposición del servicio de millones en $\mathbf{1 5 9 0 ,}$ prorrogado en 1596 y elevado de 8 a 18 millones de ducados en $1601^{11}$. El aumento de la presión fiscal coincidió con una recesión económica general cada vez más evidente y recayo sobre unos concejos muy inestables políticamente y

8. Sobre todo este tema siguen pareciéndome insuperables las páginas que le dedica DOMÍNGUEZ ORTIZ,A. 1970, especialmente el capítulo "La función político-social de la nobleza".

9. Archivo Municipal de Logroño, leg. 27 , doc. 7.

10. Dos buenas síntesis sobre las consecuencias de la presión fiscal en la segunda mitad del XVI: GARCÍA SANZ,A. invierno 1984, pp. 21-23. VASSBERG, D. 1986, pp. 283-290.

11. Cfr., ULLOA, M. 1963, pp. 118-128; y ARTOLA, M. 1982, apéndice $\mathbf{n}^{\circ}$ IV. 
cargados de deudas. Las medidas recaudatorias que los grupos dirigentes se vieron obligados a adoptar -imposición masiva de impuestos indirectos, privatización de bienes comunales, cobro directo por prorrateo entre los vecinos (repartimientos), etc.- generaron las primeras movilizaciones antioligárquicas con objetivos antifiscales.

También la situación financiera de la Corona está detrás de la venta masiva de baldíos $^{12}$ y de la enajenación de un buen número de localidades pertenecientes a las Ordenes Militares, conventos y cabildos ${ }^{13}$, aprovechando las bulas papales de 1529, 1551 y 1574. Las ventas trajeron consigo importantes consecuencias sociales, posibilitando el acceso a la nobleza señorial de funcionarios, mercaderes y miembros de las oligarquías urbanas ${ }^{14}$, pero también fomentando un aumento de la crispación popular, no sólo por el hecho de caer bajo dependencia señorial, sino también porque, a partir de 1557, se concedieron importantísimas atribuciones jurisdiccionales a los nuevos señores a costa de los derechos tradicionales de los concejos enajenados ${ }^{15}$.

Por último, el sistema judicial castellano se había convertido en un peligro real para la nobleza señorial desde las reformas de los Reyes Católicos y de Carlos I -como lo prueban las sentencias que dictaron las Chancillerías hasta finales del XVI-, y esto, entre otras razones, influyó en los objetivos políticos que inspiraron la reforma de las funciones judiciales del Consejo de Castilla que llevó a cabo Felipe II en 1598. Se creó la Sala de Justicia o Sala de Mil Quinientas, convirtiéndola en un tribunal de apelación sobre las sentencias de las Chancillerías y, además, se empezó a recurrir de forma masiva al envío de jueces de comisión, que dependían directamente del Consejo y apartaban los casos políticamente más importantes de la jurisdicción de los tribunales ordinarios.

El Consejo de Castilla, incluida su Sala de Justicia, se convertiría en un tribunal eminentemente político, destinado a congelar o modificar aquellas sentencias cuya aplicación hubiese podido suponer un riesgo político al atentar contra los intereses de la aristocracia o ser incompatibles con la estrategia política que la Corona siguiese en ese momento ${ }^{16}$. Fue, desde luego, el principio del fin del prestigio que habían gozado hasta entonces los tribunales reales, pero también

12. Vid., VASSBERG, D. 1983.

13. Estas enajenaciones, aparte de frustrar las expectativas de muchas localidades de permanecer bajo el patronazgo real, significó en buena parte de los casos un recrudecimiento de la presión señorial, tanto por las condiciones en las que se vendieron como por los intentos de los compradores de rentabilizar su inversión. Vid., MOXO, S. de. 1961, pp. 327-361.

14. Sólo dos linajes de la alta nobleza, los de la Cerda -duques de Medinaceli- y los Mendoza -duques del Infantado- participaron en las compras. Cfr, MOXO, S. de 1961, pp. 358-361.

15. Cfr., GUILARTE,A.M. 1962, pp. 249 y 443

16. Como es sabido, los propios consejos estaban supeditados a la labor de los secretarios de des-pacho, y a partir del siglo XVII por los validos, las juntas especiales y las secretarías. Esto significaba, además de un instrumento de control del aparato del Estado por los validos y la alta nobleza, un nuevo filtro político a las decisiones de los Consejos. Cfr., TOMÁS Y VALIENTE, F. 1982, pp. 31-68 
una forma de hacer compatible la estructura administrativa y gubernativa estatal con los intereses de los grupos sociales que de hecho la sostenían: las élites urbanas y la alta nobleza señorial.

Desde un punto de vista económico, la coyuntura expansiva toca techo entre 1550 y 1580 , dependiendo de zonas y de sectores. En el campo, a los problemas que afectan directamente a la producción -cierto grado de superpoblación y caída de la productividad-, se viene a sumar la incidencia del capitalismo mercantil. El dinero, los circuitos comerciales y las maniobras financieras y especulativas aumentaron los problemas de abastecimiento, encarecieron la tierra y se convirtieron en un instrumento más de extracción de rentas al campesinado ${ }^{17}$.

La economía familiar de autoconsumo será atacada por todos lados: la privatización de terrenos comunales; la imposición de impuestos directos e indirectos, no sólo para pagar al rey, sino cada vez más para hacer frente a los intereses de las deudas que acumulaban los concejos; los préstamos privados, que exigían hipotecar la hacienda familiar; el aumento espectacular de las tasas de arrendamiento; y un proceso menos conocido, pero probablemente de los más importantes, la implantación de políticas agrarias al servicio exclusivo de los grandes propietarios, profundamente imbricados en una agricultura comercializada, y que aplicarán políticas tendentes al monocultivo a costa de las tradiciones comunitarias y que incluso, para garantizarse una mano de obra jornalera numerosa y barata, no dudarán en impedir, no sólo el aumento de los jornales, sino incluso las roturaciones, la venta al por menor y todas aquellas prácticas que servían para complementar los ingresos familiares y liberaban a los campesinos pobres del trabajo asalariado ${ }^{18}$.

A finales del siglo XVI todos los indicadores son negativos en el campo, y sobre este panorama inciden una oligarquización creciente, una presión fiscal en aumento y, por último, la peste de 1599 y las malas cosechas que se suceden en los últimos veinte años ${ }^{19}$.

De cualquier modo, no fue en el mundo rural donde se produjeron las tensiones sociales más graves. Probablemente, los campesinos del XVI, aunque sus formas de vida tradicionales se viesen acosadas, eran menos sensibles a la fluctuaciones económicas de lo que a menudo se ha supuesto. Además, otros procesos de tipo político, institucional y cultural llegaban muy mitigados a las comunidades rurales; incluso los intentos señoriales por aumentar su poder y sus ingresos se concentraron en las ciudades y villas de cierto nivel, dejando de lado a los pequeños pueblos de los que pocos beneficios cabía esperar.

17. Vid., SALOMON, N. 1964, pp. $245-248$

18. Un par de ejemplos en los que se demuestra el carácter deliberado que tenían estas políticas municipales: GÓMEZ URDÁÑEZ, JL. (dir.) 1986; y LORENZO CADARSO, P.L. 1994

19. Cfr., VASSBERG, D. 1986, p. 254 
Las grandes víctimas entre el campesinado -o, al menos, los grupos que más conflictos protagonizaron- fueron los jornaleros y los pequeños propietarios radicados en zonas altamente integradas comercialmente. La inflación y la imposición de impuestos indirectos castigó de forma muy especial a los jornaleros, que desde mediados de siglo intensificaron sus demandas, provocando con ello serios conflictos en las zonas donde la mano de obra era fundamental para sostener la rentabilidad de las explotaciones agrarias - por ejemplo, en las comarcas vinícolas ${ }^{20}$.

En general, los últimos cuarenta años del siglo XVI parece que se caracterizaron por un aumento de las desigualdades, un proceso que arrastró a un elevado número de pequeños propietarios al jornalerismo ${ }^{21}$. La creciente inseguridad en que vivían los sectores sociales en trance de caer en el trabajo asalariado, agravada por la diversidad de intereses entre los distintos grupos socioprofesionales de cada localidad y por el comportamiento interesado de las oligarquías locales, generó una oleada de conflictos populares con objetivos estrictamente corporativos, aunque el enemigo será siempre la élite campesina de cada localidad:pequeños ganaderos en contra de las roturaciones y de las restricciones en el acceso a los pastos comunales; pequeños propietarios agrarios contra los ganaderos por los privilegios mesteños o por la ultraprotección de los pastizales; disputas entre propietarios por el reparto del agua de riego; movilizaciones jornaleras; etc.

Por último, el crecimiento extensivo de la producción agraria ${ }^{22}$ llevó a una mayor competencia entre localidades vecinas a cuenta de los repartos de agua, pastos y otros bienes de uso o propiedad compartida. Los enfrentamientos armados y otros tipos de lucha se hicieron frecuentes ya que las concordias firmadas en la baja Edad Media eran consideradas como una traba para las localidades más dinámicas.

La evolución de la economía mercantil y manufacturera, por su parte, cambió de signo en la segunda mitad del siglo. Cronológicamente, los primeros síntomas de recesión fueron los graves problemas financieros de 1550 , con quiebras en cadena de un gran número de mercaderes. Después vendría el cierre de los mercados laneros del norte tras iniciarse las guerras con Holanda, apenas compensado con la apertura de nuevas rutas - por tierra a través de Francia-, nuevos mercados -Italia- y nuevos productos de exportación -los mercaderes de Logroño intentaron sin éxito exportar vino de Rioja a Flandes-. Nada evitó una recesión generalizada: entre 1530 y 1580 la cabaña mesteña había perdido un $30 \%$ de sus efectivos.

Los problemas de la economía mercantil y manufacturera, unidos a las crecientes dificultades que encontraba la burguesía en sus intentos de ascender

20. Vid., LORENZO CADARSO, P.L. 1989.

21. Cfr., BRUMONT, F. 1984, pp. 225-231.

22. Un ejemplo difícil de mejorar sobre el proceso de crecimiento extensivo de la agricultura es el de Horche. Vid., GARCÍA FERNÁNDEZ, J. 1953, pp. 193-239 
socialmente, fomentaron un trasvase de grandes capitales desde los negocios financieros y mercantiles hacia la deuda pública o privada -juros y censos- y hacia la compra de tierras ${ }^{23}$. Es el fracaso del capitalismo castellano, aunque su agonía pueda rastrearse mucho tiempo después.

Los cambios sociales que se producen durante la segunda mitad del siglo XVI son claves para entender buena parte de los conflictos sociales que se produjeron a partir de entonces. Entre 1550 y 1640, la burguesía enriquecida en los mejores años del capitalismo castellano intenta que su preponderancia económica se traduzca en poder económico y prestigio social: sus primeros objetivos serán los concejos, los estamentos hidalgos y la universidad. Serán unos objetivos que la conducirán a fundirse, tras unos breves intentos de crear una aristocracia del dinero en las ciudades, con la nobleza de sangre.

Las reacciones a este proceso tendrán enorme trascendencia: el pueblo llano, al que se ven conducidos buena parte de los hidalgos de sangre residentes en las ciudades, reaccionará con dureza porque el ascenso social de la burguesía precisaba de la imposición de gobiernos oligárquicos. La baja nobleza, por su parte, mantuvo una actitud formalmente hostil, incluso agresiva, pero, de momento, no tenía muchas posibilidades de impedir los objetivos burgueses: era muy difícil, por ejemplo, impedir que los conversos de Cuenca o Guadalajara terminasen por acceder a la nobleza; no sólo eran ricos, sino que también eran poderosos: en Cuenca siempre hubo un converso entre los procuradores de Cortes desde 1515 hasta finales de siglo ${ }^{24}$ :

$\begin{array}{ll}\text { A N O } & \text { PROCURADOR CONVERSO } \\ 1515 & \text { Hernando Alonso Chirino } \\ 1520 & \text { Juan Alvarez Toledo } \\ 1538 & \text { Antonio Alvarez Ayala } \\ 1542 & \text { Fco.Alvarez Toledo y Luna } \\ 1555 & \text { Juan Montemayor } \\ 1563 & \text { Juan del Collado } \\ 1566 & \text { Juan Zárate } \\ 1573 & \text { Juan Montemayor y Andrés de la Mota } \\ 1576 & \text { Diego Cetina } \\ 1579 & \text { Miguel Muñoz y Juan Montemayor } \\ 1588 & \text { Juan Pedraza } \\ 1598 & \text { Fco. Eugenio Zúñiga }\end{array}$

23. Vid., VASSBERG, D. 1986, pp. 193-196; BRAUDEL, F. 1976. DOMÍNGUEZ ORTIZ,A. 1973, pp. 424-425. SALOMON, N. 1964, pp. 165-176.

24. Los nombres de los procuradores proceden de las Actas de las Cortes de Castilla, 45 vols., Imprenta Nacional, Madrid, 1869-1918. El origen converso se ha reconstruido a través de las investigaciones genealógicas para la consecución de hábitos de las órdenes Militares (A.H.N., Ordenes, exps. Santiago,Alcántara y Calatrava). Sobre su utilidad como fuente vid., BURGOS ESTEBAN, F.M. 1992, pp. 287-290. 
En cuanto a su riqueza, véase el caso de los mercaderes de Logroño: 11 de ellos tenían ingresos anuales superiores a los 3.000 ducados y, sin apenas duda alguna, el más pobre de todos superaba en mucho a los hidalgos más ricos; baste una comparación con los grupos artesanales mejor situados económicamente de la ciudad por esas fechas (1596) ${ }^{25}$ :

\begin{tabular}{rlc} 
NUMERO & ESPECIALIDAD & $\begin{array}{c}\text { INGRESOS } \\
\text { ANUALES MEDIOS }\end{array}$ \\
\hline 8 & mercaderes hierro & 2.187 ducados \\
43 & mercaderes paños & 1.265 \\
13 & Fruteros & 56 \\
5 & Olleros & 66,6 \\
12 & Herradores & 78 \\
6 & Cordoneros & 55,3 \\
3 & Silleros & 63,3 \\
9 & Sogueros & 66,2 \\
7 & Confiteros & 907 \\
6 & Curtidores & 1.166 \\
36 & Mesoneros & 463 \\
8 & Calceteros & 100 \\
31 & Zapateros & 93,3 \\
5 & Boteros & 92 \\
2 & Pellejeros & 70
\end{tabular}

En tres de las ciudades que he estudiado con más profundidad -Logroño, Cuenca y Guadalajara-, los grupos burgueses, que hasta $1540-1550$ se contentaban con ejercer el poder político, empiezan a modificar drásticamente su comportamiento social: inician de forma masiva la fundación de mayorazgos $y$ capellanías y acuden a la Sala de Hijosdalgo de la Chancillería en busca de ejecutorias de hidalguía ${ }^{26}$.

Un caso realmente importante es de la poderosa comunidad conversa de Cuenca. Hasta mediados del XVI, pese a la presión del Sto. Oficio -incluso varios regidores conversos fueron procesados-, mantienen escasísimos contactos con los cristianos viejos. Los matrimonios, los negocios mercantiles y las cesiones de cargos municipales se hacen dentro de la comunidad conversa. Viven todos, con pocas excepciones, en el antiguo barrio judío -el Alcázar- y acuden para todos los actos religiosos a la antigua sinagoga reconvertida en iglesia -Sta. María de

25. Archivo General de Simancas, Exps. de Hacienda, $n^{\circ} 307$. Agradezco a N.Armas Lerena, de la Universidad de La Rioja, que me haya proporcionado esta documentación.

26. En Guadalajara, donde el duque del Infantado, a pesar de las Leyes de Córdoba, poseía la Alcaldía de Padrones, la forma de lograr una sentencia favorable era entrar al servicio del duque o de sus parientes. 
Gracia-.Todo cambiará drásticamente entre el último tercio del XVI y el primero del $\mathrm{XVII}^{27}$.

En ocasiones, los grupos burgueses eran lo suficientemente poderosos como para imponer sus intereses de forma institucionalizada. En Logroño se firmó un acuerdo en 1560 entre hidalgos y mercaderes rompiendo el monopolio que los hidalgos de sangre tenían sobre el estamento desde 1500, a partir de entonces serían reconocidos como hidalgos todos los que tuviesen ejecutoria de hidalguía ${ }^{28}$, lo que posibilitó acceder a la condición noble a todos los mercaderes ricos. En Cuenca, dado el origen converso de buena parte de la élite local no hidalga, las cosas parecían más difíciles, pero, de hecho, en 1536 se elaboró el último padrón fiable de hidalgos - al que se aferrarían desde entonces con uñas y dientes todos los conversos-; hasta entonces los regidores conversos se habían conformado con el poder, pero aquel año exigieron revisar personalmente el padrón municipal y el Ayuntamiento, pese a la oposición del corregidor y de los representantes populares, apoyó la propuesta por unanimidad ${ }^{29}$.

El regidor que presentó la demanda fue Alonso Alvarez de Alcalá, conocido converso, perteneciente a la familia de origen judío más odiada de todos los tiempos en las ciudades de Cuenca y Guadalajara. El origen de esta familia está en Toledo -en el XV se extenderían por Cuenca, Guadalajara y Alcalá de Henares-, de donde salió Alonso Alvarez, convertido él o su padre a comienzos del siglo XV, y que ejerció como Contador Mayor de Juan II y de Enrique IV -su hijo Juan continuaría en el cargo hasta que fue desterrado por Isabel durante la guerra civil-, el cual premió sus servicios con regimientos diversas rentas, regimientos perpetuos en Cuenca y Guadalajara e incluso le llegó a nombrar hidalgo en 1415:

\footnotetext{
"Por cuanto he seído informado -decía el privilegio- que los del vuestro linaje, cuando eran judíos, eran habidos por fijosdalgo entre ellos e porque pues vosotros sois cristianos, es razón que seades más honrados" ${ }^{30}$.
}

Doscientos años después de la muerte de don Alonso Alvarez, los hidalgos de Guadalajara no perdían ocasión de quejarse airadamente de que en la capilla que

27. Este proceso lo he reconstruido utilizando las investigaciones genealógicas del Consejo de Ordenes realizadas en Alcalá de Henares, Guadalajara, Cuenca, Huete y Toledo (los conversos de todas estas poblaciones mantenían constantes enlaces matrimoniales, lo cual permitiría hablar de una comunidad conversa manchega).

28. A.H.N., Consejos, leg. 28.172 y Archivo Municipal de Logroño, leg. 22, doc. 7.

29. El interesante trabajo de R. Carrasco sobre los hidalgos de Cuenca no tiene en cuenta estos hechos -ni otros parecidos que se produjeron luego- para explicar el aumento de los hidalgos -un $7 \%$ en 1537 y un 12,8\% en 1598-, de ahí que le resulte difícil explicar el hecho de que sea en los barrios judíos donde más alto sea el porcentaje de hidalgos; de hecho sólo puede decir que había una evidente contradicción entre las formulaciones teóricas sobre la hidalguía y la condición social real de los hidalgos; tampoco es extraño que no encuentre padrones anteriores a 1537. CARRASCO, R. 1989.

30. A.H.N., Ordenes Militares, Santiago, exp. $\mathrm{n}^{0} 2.043$. 
fundó para su enterramiento en la catedral siguiera colgando un rótulo que decía: AQUI YACE EL MUY ILUSTRE SEÑOR DON ALONSO ALVAREZ.

Los pactos o las imposiciones sólo eran aceptados por la baja nobleza cuando el poder político se les había escapado de las manos -en 1560, por ejemplo, Logroño estaba gobernada por 12 regidores perpetuos, todos mercaderes-, pero, de forma extrainstitucional, que no era menos eficaz, las vinculaciones clientelares y los matrimonios de conveniencia terminaron por fundir en un sólo grupo social a la burguesía y a la baja nobleza. Incluso cabe decir que, en las ciudades, de todos los hidalgos de origen medieval sólo conservaron su rango aquellos que lograron buenos matrimonios y los que poseían grandes patrimonios, el resto fueron relegados a la condición plebeya.

Los acuerdos institucionalizados o privados no evitaron en absoluto que este proceso generara importantes tensiones, que desbordaron rápidamente el marco local para convertirse en un problema de alta política. Se crearon toda una serie de barreras, institucionalizadas o meramente culturales, contra este grupo social, formando una auténtica reacción feudal que, si bien fracasó a la hora de frenar a la burguesía enriquecida en el XVI, sí que impidió que las nuevas generaciones burguesas surgidas a partir de finales de siglo siguieran su mismo camino. Todo este entramado legal e ideológico pesó como una losa sobre el capitalismo castellano y arrastró a la burguesía del XVII a adoptar posturas políticas populistas e igualitaristas -Logroño y Huete en torno a 1645 son dos ejemplos excelentes-.

Por su parte, la alta nobleza inicia una dramática escalada de endeudamiento, producto, por un lado, de la imposibilidad de aumentar sus rentas ante la respuesta popular, apoyada institucionalmente por el sistema judicial real; y por otro, de una coyuntura inflacionista que reduce en términos reales los ingresos señoriales, precisamente en un momento en el que entran en escena los cortesanos de origen burgués o de la baja nobleza, lo que exige aumentar los gastos de ostentación ${ }^{31}$. Los intentos señoriales por reajustar la estructura jurisdiccional y por aumentar los ingresos en sus dominios les llevaron, dado que la generosidad monárquica se había terminado en ese aspecto, a usar las mismas estrategias de siempre: apropiarse de nuevas rentas y derechos jurisdiccionales confiando en la operatividad de la coacción a los vasallos y en la ineficacia de la Corona para proteger su patrimonio. Pero, como dice Bartolomé Yun, habían terminado los tiempos de la espada y comenzado los de la ley y el pleito; nuevos tiempos que impedían el éxito de las estrategias basadas en la fuerza. Se producirá una oleada de movilizaciones antiseñoriales, la más intensa de los siglos XVI y XVII, de la que saldrán muy perjudicados los señores: a comienzos del XVII la

31. Los dos trabajos fundamentales sobre este proceso son: YUN CASALILLA, B. 1985, pp. 443$471 ; y$ YAGO, Ch. 1982. 
nobleza señorial está ya a la defensiva, sólo la protección monárquica impide su derrumbe.

\section{TERCERA FASE: $1609-1620$}

Los veinte primeros años del XVII son, probablemente, uno de los perioclos económicamente más desfavorables de todo el Antiguo Régimen castellano. De hecho, las dos últimas variables económicas que se habían mantenido incólumes durante la recesión de finales del XVI, las inyecciones financieras procedentes de América y la solidez y reputación internacional de la moneda castellana, comienzan a derrumbarse por esos años.

Las desdichas económicas, contra lo que podría esperarse, no provocaron un aumento de las tensiones sociales, aunque también es cierto que otros factores colaboraron a crear un ambiente de calma social: sobre todo un comportamiento de las instituciones que renuncia a todo proyecto que pueda alterar la situación sociopolítica y una evolución de los principales grupos sociales menos dislocadora que en el pasado.

El reinado de Felipe III, monarca calificado, con razón, por A. Domínguez Ortiz como el más inútil y nefasto de todos los Austrias $^{32}$, tuvo parecidos objetivos en política exterior e interior. Prudencia e intencionalidad conciliadora o, probablemente, incompetencia y miedo a tomar decisiones, consecuencias habituales de las coyunturas políticas en las que la inercia y la corrupción reemplazan a los grandes proyectos y las fiestas a las victorias; un abogado catalán los explicaba así en 1615:

"En resumen, nuestro buen rey es un santo, pero no concluye nunca con sus escrúpulos. Sus ministros prefieren jugar toda la noche y levantarse a mediodía que ocuparse de la guerra.Así hoy no se habla de otra cosa que de las fiestas del duque de Lerma. ¡Y que se queje quien le duela!"33.

Reconstruir el ambiente de inmoralidad, de incompetencia y de falsedad que se respiraba en la Corte de Felipe resulta para un español de 1996 no sólo morboso, sino incluso arriesgado. Los grandes proyectos políticos del pasado fueron puestos en cuarentena, pero ni se renunció explícitamente a ellos ni se tomaron medidas drásticas para reorientar la política: el objetivo de construir una Europa católica por la fuerza de las armas, aun considerándose una causa perdida, siguió repitiéndose como consigna en las misas y los desfiles y, lejos de abrir nuevas estrategias geopolíticas, todo quedó en una serie de tratados de paz que no significaban un cambio de rumbo, pero ofrecían un paréntesis; el objetivo de la una-

32. DOMÍNGUEZ ORTIZ,A. 1973, pp. 363-364.

33. Cit., en VILAR, P. 1974,"El tiempo del Quijote", p. 337. 
nimidad católica se abandonó en Europa -incluso se permitirá a los herejes europeos practicar su religión en España-, pero en el interior se mantiene con renovados ímpetus: los moriscos son expulsados; la decadencia económica del reino se acepta como un hecho consumado, pero lejos de dar lugar a medidas políticas serias, lo que surge es un aluvión de memoriales en los que las aportaciones de interés quedan ocultas por un manto de sueños, lágrimas o meras insensateces; se sabe que la presión fiscal ha desbordado el límite de lo tolerable, pero en lugar de reformar el sistema, lo que se hace es no aumentar el volumen de los impuestos. La lista sería interminable.

La política hacia los concejos es un excelente ejemplo de todo lo dicho. A finales del XVI todo el mundo aceptaba que la oligarquización estaba poniendo en peligro no sólo el bienestar del pueblo, sino incluso la solvencia financiera de los municipios. La política coherente hubiese sido, lógicamente, eliminar los instrumentos legales en los que se apoyaba la oligarquización, fundamentalmente las perpetuaciones. De hecho, en los primeros años del reinado se consienten los consumos de oficios, en parte por inercia de la política iniciada por Felipe II en 1596 y en parte porque ahora el Consejo parece estar decidido a impedir que los oficios perpetuos sigan en manos de "gente de baja suerte, con mucha bacienda y dineros adquiridos en mercancías y tratos viles, y se querrán ennoblecer con ellos y mandar en las repúblicas ${ }^{\prime 34}$, como habían pedido los hidalgos desde mediados del XVI. Pero a medida que las élites locales empiezan a protestar, la actitud de la Corona se vuelve más y más timorata: no se atreve a negar el derecho a consumir los oficios, pero tampoco se atreve a incentivar estas prácticas.

En 1609 se llega a una solución típica del momento: por Real Cédula se autoriza el consumo de los oficios acrecentados - una minoría- y el de algunos cargos relacionados con la recaudación de impuestos -tesoreros, depositarios y escribanos-, pero, ante el temor de provocar una oleada de movilizaciones antioligárquicas que alteraran la estabilidad política de los concejos, pocos meses después otra Real Cédula prohíbe cualquier modificación en el sistema de gobierno $^{35}$. Lo más significativo es que no sólo se prohíben los consumos, sino que se hace otro tanto con las perpetuaciones. En suma, ni se abordan las medidas antioligárquicas que exigía la situación, ni se apoya sin titubeos a las oligarquías; lo que se pretende es, lisa y llanamente, no cambiar nada, mantener la situación heredada por miedo a provocar conflictos.

El reinado de Felipe III fue en los concejos un compás de espera durante el cual se arruinó el prestigio del sistema judicial y de la mayoría de las instituciones reales. Lo que no se evitó, por supuesto, fue que las élites locales fuesen acrecentando su poder y que, a falta de recursos legales, recurrieran a la coacción y

34. Así opinaba, con medio siglo de retraso, el Marqués de Poza, Presidente del Consejo de Castilla, en 1600. Cit., en DOMÍNGUEZ ORTIZ,A. 1984, p. 172.

35. Cfr., MORENO GARBAYO, N. 1977, vol. I, año 1609. 
a las represalias; tampoco que entre el pueblo cundiera unas veces la desesperanza y otras un creciente radicalismo que estallaría años después.

Cosas parecidas pueden decirse del sistema señorial. Los pleitos iniciados por las localidades rebeldes a mediados del XVI estaba ya apelados en su mayoría en segunda suplicación ante la Sala de Justicia del Consejo, normalmente intentando retrasar o impedir que las sentencias antiseñoriales de las Chancillerías se ejecutasen. La Corona prácticamente no toleró que se sentenciase un sólo pleito, los trámites procesales se fueron retrasando y en 1620 seguían sin resolución definitiva. Era, por tanto, una actitud sumamente ambigua en la que el Consejo, al renunciar a sus responsabilidades políticas, convertía al juego de fuerzas que hubiese en cada localidad en el árbitro de la situación.Allá donde los señores tropezaron con poblaciones decididas y bien organizadas, todos sus derechos pendientes de sentencia les eran negados, y justamente lo contrario sucedía donde los señores eran capaces de imponer sus intereses por la fuerza. El descrédito y la desconfianza que el pueblo empezará a sentir hacia el sistema judicial real fomentará la adopción de estrategias de lucha cada vez más alejadas de los cauces que ofrecía la legalidad: a partir de este momento, contra lo que había sido habitual el siglo anterior, los conflictos antiseñoriales darán lugar con frecuencia a actos violentos.

Desde un punto de vista social, todos los procesos iniciados en la fase anterior están en periodo conclusivo. Son los años dorados de las élites urbanas; si para finales del XVI ya habían controlado oligárquicamente los concejos y formaban parte de los estamentos hidalgos, a partir de ahora entrarán de forma masiva en la burocracia absolutista, empezando a ejercer altos cargos en la Corte y a recibir las primeras recompensas. De todos modos, estas sólo llegarán en masa a partir del reinado de Felipe IV, primero hábitos de las Ordenes Militares, luego, ya bajo Carlos II, títulos nobiliarios.

La alta nobleza, que había sufrido un proceso de endeudamiento masivo en la segunda mitad del XVI, empieza a pasar por serios apuros financieros. Algunas casas quiebran, pero todavía son pocas, porque las mercedes que otorga la Corona salvan a muchos de forma individual y, además, el Consejo de Hacienda todavía no ha puesto sus ojos en las rentas reales usucapidas por la nobleza señorial -lo hará en 1632-.

\section{Cuarta Fase: 1620-1665}

Entramos en el periodo álgido de la conflictividad social castellana, que coincide en líneas generales con la llamada "época de los disturbios" a nivel europeo. Las coincidencias del caso español con el resto de Europa son muy elevadas: las guerras; la presión fiscal; el aumento de las tensiones en torno al Absolutismo; la angustiosa situación de la nobleza, acosada por la ruina financiera y la competencia política de la burocracia; el malestar popular contra el régimen señorial y 
las oligarquías urbanas; el descrédito de las instituciones y en general del grupo dirigente; la profunda recesión económica; los desajustes sociales provocados por el empobrecimiento de amplios sectores y el ascenso social de la burguesía.

Obviamente, aunque coincidan buena parte de las causas, las distancias son amplias en cuanto a la conflictividad concreta que generaron las tensiones sociales y de otro tipo. La gravedad de los conflictos castellanos fue notablemente inferior, y creo demostrar en este trabajo las razones que lo explican, entre las que destacaría las siguientes: una actitud del Estado Absoluto mucho más prudente que en el resto de Europa; un régimen señorial con escasa capacidad de coacción; una excelente aculturación de las masas populares; y una profunda coincidencia de intereses entre el patriciado urbano de origen burgués, la vieja nobleza de sangre y el Estado Absoluto.

Ninguno de estos procesos hubiese podido evitar el estallido de sublevaciones graves si el capitalismo hubiera seguido una evolución ascendente en el XVII y si la ortodoxia ideológica hubiese sido defendida con menos eficacia. Explicar estas realidades exige un planteamiento globalizador, que no olvide la labor de las instituciones -el Sto. Oficio, la burocracia estatal, los concejos, la organización del sistema señorial, la Iglesia, etc.-, los problemas económicos a los que se enfrentan las actividades mercantiles y manufactureras, y el sometimiento de la cultura.

La política de Felipe IV, siempre condicionada por las necesidades financieras que imponían las guerras exteriores y por los problemas estructurales del sistema fiscal, llegó a sobrepasar los límites que parecía aconsejar la prudencia. Hubo dos décadas, 1630-1650, en las que ni la alta nobleza se sentía segura. La voracidad recaudatoria alteró el relativo equilibrio vigente desde comienzos de siglo: la puesta en venta de alcabalas, oficios y jurisdicciones, la concesión masiva de hábitos de Ordenes Militares a las élites urbanas para que respaldasen las medidas gubernamentales y otras prácticas provocaron un aumento inusitado de las tensiones sociales. En la segunda mitad del XVI, cuando las tensiones no fueron mucho menores -al igual que en Europa-, pudo mantenerse el orden gracias al prestigio y la estabilidad de las instituciones, pero ahora no existía esa posibilidad.

El descrédito de todo el entramado institucional no sólo provocaba indefensión en los grupos sociales más desprotegidos, también fomentaba los posicionamientos radicalizados y los intentos de defender sus intereses por la fuerza. Este descrédito llegó, en situaciones extremas, a alcanzar al propio rey: Fuenteguinaldo en 1620,Alcántara en 1630 y Azuqueca de Henares en 1629 serían algunos ejemplos.

A la presión fiscal directa -los distintos servicios ${ }^{36}$ - se le sumaron una serie de arbitrios extraordinarios - papel sellado, monopolios de ciertos productos,

36. Sólo el dinero recaudado en el servicio de millones sumó 226 millones de ducados -incluyendo el servicio de 1619, que se pagó en 1620-, es decir, en torno a los 6 millones de ducados al año. En el reinado anterior se pagaron por el mismo concepto unos 2,5 millones al año. $C f r$., ARTO LA, M. 1982, elaboración propia a partir de los datos que ofrece en pp. 468-475. 
ventas de oficios, de jurisdicciones y de alcabalas- y una gran parte de la carga cayó sobre los concejos, la mayoría de los cuales estaban atravesando serios apuros financieros desde finales del $\mathrm{XVI}^{37}$. Fue necesario recurrir al establecimiento de sisas sobre la mayoría de los productos de consumo popular, encareciendo los precios, -a partir de 1655, ante las reticencias de algunos concejos a imponerlas, éstas se hicieron obligatorias- o recaudar el dinero mediante repartimientos, mucho más odiados todavía por el pueblo.

El aumento de la presión fiscal volvió mucho más intolerable el comportamiento de las oligarquías locales, a las que el pueblo responsabilizaba de todos los problemas financieros de los concejos. Unas veces esta situación desembocó en movilizaciones antioligárquicas y otras, para desesperación del Consejo de Hacienda, en una política recaudatoria municipal que prefería acumular atrasos que provocar al pueblo con un aumento de la presión fiscal.

Para 1625 ya no bastaba con aumentar el volumen de los impuestos ordinarios y se acudió entonces, como en la segunda mitad del XVI, a la enajenación del patrimonio real y a estrategias recaudatorias más duras, más impopulares y, lógicamente, más imprudentes. En las Cortes de 1625 se autorizó la venta de 20.000 vasallos de realengo, otros 12.000 en 1630 y otros 8.000 en 1638 . A partir de los años treinta comenzaron también a venderse privilegios de villazgo, pagados a precio de oro por las aldeas segregacionistas o por las villa y ciudades de las que éstas dependían para impedírselo ${ }^{38}$.

Los nuevos señoríos generaron un alto número de tumultos antiseñoriales y las segregaciones intensificaron los enfrentamientos entre localidades vecinas por el reparto de los bienes comunales. En ambos casos, tanto la estructura económica como la social preexistentes se veían dislocadas, el empobrecimiento general y el reforzamiento de las oligarquías aldeanas solían ser los resultados más frecuentes.

En los años treinta se inicia la guerra de Mantua y la intervención militar de Suecia y Francia en el conflicto, de modo que ya no basta con los ingresos de los años veinte, hay que aumentarlos. En 1630 se inicia la campaña de venta de oficios más imponente habida hasta entonces; allá donde había una élite local -en ocasiones sólo podría hablarse de un par de vecinos ambiciosos- deseosa de consolidar su papel oligárquico, se pusieron a su disposición los oficios municipales, incluso los de representación popular. Estas ventas fueron controladas desde un principio por la baja nobleza local, cerrándose así la última puerta entreabierta que les quedaba a los plebeyos ricos. Estos no dudaron en encabezar movilizaciones populares antioligárquicas -Calahorra, Alfaro, Huete, Logroño- que dieron lugar a tumultos extremadamente graves en muchos casos.

37. DOMÍNGUEZ ORTIZ,A. 1985, "La ruina de la aldea castellana”.

38. DOMÍNGUEZ ORTIZ,A. 1964, pp. 163-207. 
La baja nobleza urbana recibió así el último y definitivo espaldarazo para su consolidación como élite local oligárquica.

La voracidad de la Hacienda Real dio un salto cualitativo en 1632: se inició un plan de reintegración y posterior venta de las alcabalas cobradas ilegalmente por la nobleza señorial. Las localidades rebeldes encontraron un nuevo instrumento de lucha, muchas se negaron a seguir pagando a sus señores, saqueando los edificios señoriales y apaleando a los recaudadores, otras pujaron por la compra de las alcabalas, encareciéndolas y obligando al señor a desembolsar cantidades que las hacían irrentables o, cuando menos, les conducían a la quiebra. Los fiscales del Consejo de Hacienda rara vez se atrevieron a iniciar de oficio los trámites de reintegración, pero apoyaron judicialmente a las villas rebeldes. Fue un golpe durísimo para muchos miembros de la alta nobleza, que arrastraban ya enormes dificultades financieras.

Otras veces, sobre todo en los pequeños señoríos, la fiscalidad desniveló la balanza de poder en favor de la nobleza. La compra de las alcabalas y de las jurisdicciones de tolerancia por los señores reafirmó su poder, permitiéndoles cometer un elevado número de abusos y apropiaciones que generaron movilizaciones populares.

El aumento de la fiscalidad se produjo además en una coyuntura económica muy desfavorable, con dos recesiones graves -1621-28 y 1640-52- a las que se sumaron los efectos devastadores de las alteraciones monetarias, las bancarrotas, las incautaciones de plata y las restricciones al comercio exterior.

Los conflictos sociales de este periodo tienen un denominador común, desconocido en Castilla hasta entonces: las disputas se dilucidan frecuentemente recurriendo a la violencia y sólo ocasionalmente las protestas se canalizan a través de pleitos judiciales u otros mecanismos institucionalizados. En los señoríos la nobleza esta casi siempre a la defensiva, carece de recursos financieros o legales con los que coaccionar a las poblaciones rebeldes. El desmoronamiento de la autoridad señorial en las localidades con élites poderosas alcanza niveles escandalosos: el señorio de Aguilar está, en la práctica, amotinado durante unos diez años -entre 1650 y 1660 , aproximadamente-; y otro tanto sucederá en las poblaciones riojanas del duque de Nájera entre 1640 y 1650. No se pagan las rentas y los representantes del señor sufren tantos atropellos que el reclutamiento de oficiales llega a ser enormemente dificultoso.

Los conflictos en el seno de los concejos entran en una fase eminentemente popular y radicalizada, sobre todo en las formas de lucha. Los plebeyos ricos se ven incapaces de acceder al grupo dirigente, que lo forma ya una élite cerrada de composición estrictamente noble, de modo que las típicas luchas por el poder entre nobles y burgueses del XVI son sustituidas por movilizaciones antioligárquicas. 
El último tercio del siglo XVII, que coincide con el reinado de Carlos II, ha pasado de ser la culminación de la miseria económica, cultural y política ${ }^{39}$ a un periodo de recuperación ${ }^{40}$. Uno tras otro, todos los indicadores socio-económicos se han ido revisando, descubriéndose que, en líneas generales, estamos en una coyuntura caracterizada por un moderado crecimiento. La población y la producción agraria empiezan a presentar un signo positivo desde 1650 y otro tanto sucede con la industria manufacturera ${ }^{41}$. Incluso las actividades comerciales y financieras, sin exceptuar al comercio colonial ${ }^{42}$, se recuperan en los últimos veinte años del siglo, aunque ya nunca alcanzarán los niveles del XVI ni evitarán que Castilla sea un país ruralizado.

Desde un punto de vista político-institucional se vuelve a unos niveles prudentes de presión fiscal ${ }^{43}$, lo cual alivia la situación financiera de muchos concejos, que ven así reducirse las tensiones que generaban los impuestos indirectos sobre los artículos de consumo popular y los repartimientos. Si a esto sumamos una actitud de la Corona hacia las oligarquías locales mucho menos complaciente que en el pasado, incluso en ocasiones claramente hostil, el resultado es que la oligarquización se hizo, en líneas generales, más tolerable.

En cuanto a los señoríos, se renunció a algunas de las prácticas recaudatorias que más conflictos habían generado, como pueda ser el caso de la reintegración de alcabalas, la venta de jurisdicciones de tolerancia o la enajenación de poblaciones realengas -sólo se vendieron en todo el reinado 10.000 vasallos-. La propia ruina financiera de la nobleza, que ahora se hace si cabe más profunda, imposibilitó a los señores para ejercer políticas agresivas en sus dominios.

De cualquier modo, fueron los factores sociales los mayores responsables de la disminución de los conflictos. El pueblo llano, en la mayoría de las localidades, estaba definitivamente sometido: los fracasos de las décadas anteriores tuvieron que fomentar necesariamente el miedo y la desesperanza. No sólo se vuelven raras las movilizaciones antioligárquicas, también los demás tipos de conflictos populares. Localidades en las que no se había conocido un momento de calma social desde mediados del XVI, como sucedió en la práctica totalidad de las ciudades riojanas, viven años de inusitada tranquilidad.

39. Las tesis tradicionales en: MAURA, duque de, 1954; y PALACIO ATARD, V. 1987.

40. Una síntesis en: KAMEN, H. 1981.

41. Vid., visiones generales en: GARCÍA SANZ,A. 1972. DOMÍNGUEZ ORTIZ,A. 1970.

42. Vid., FONTANA, J. (ed.) 1982, especialmente la introducción del propio Fontana; FONTANA, J. 1955, pp. 199-219; CHAUNU P. 1984.

43. SANZ AYAN, C. 1991. 
Las oligarquías locales, que habían provocado hasta entonces la mayoría de los conflictos, se convierten en factores de estabilidad. Por un lado ya no se sienten tan apoyados por la Corona como en el pasado y, por el otro, sus tradicionales enemigos, los plebeyos ricos, especialmente la burguesía mercantil, han visto reducir su capacidad hasta dejar de ser un peligro.

La paz social del último tercio del siglo XVII está íntimamente ligada con la culminación del proceso de refeudalización. El Estado está en manos de la nobleza y de una serie de linajes de funcionarios -buena parte de ellos ya nobles titulados- que controlan férreamente las puertas de acceso -los Colegios Mayoresy los ascensos. Los patriciados urbanos son nobles que forman élites cerradas y que cada vez mantienen menos contactos con sus parientes bien situados en la Corte, son ya unas oligarquías sin grandes pretensiones de ascenso social, incluso manifiestamente empobrecidas. La burguesía es tan débil como puede esperarse de un capitalismo agónico y de una economía crecientemente ruralizada. La paz social procede, en suma, del inmovilismo. 
PEDRO LUIS LORENZO CADARSO

\section{BIBLIOGRAFÍA}

ARTOLA, M. 1982

La Hacienda española en el Antiguo Régimen. Madrid.

BRAUDEL, F. 1976

El Mediterráneo y el mundo mediterráneo en tiempos de Felipe II. Madrid, 2 vols.

BRUMONT, F. 1984

Campo y campesinos de Castilla la Vieja en la época de Felipe II, Madrid.

BURGOS ESTEBAN, F.M. 1992

"Aplicación de las pruebas de limpieza y honor para el estudio de las élites en los siglos XVI y XVII. Sus condiciones para el método prosopográfico en los estudios de historia social": La Historia social en España. Actualidad y perspectivas, Madrid, pp. 287-290

CARANDE, E. 1977

Carlos Vy sus banqueros, Barcelona.

CARRASCO, R. 1989

"Les hidalgos de Cuenca à l'epoque moderne (1537-1642)":V.AA., Hidalgos E bidalguía dans L'Espagne des XVIe-XVIIIe siècles, Paris, pp. 183-186.

CHAUNU P. 1984

Sevilla y América, ss. XVI y XVII, Sevilla.

DOMÍNGUEZ ORTIZ,A. 1964

"Ventas y exenciones de lugares durante el reinado de Felipe IV": Anuario de Historia del Derecho Español, pp. 163-207.

DOMÍNGUEZ ORTIZ,A. 1970

La sociedad española en el siglo XVII. I. El estamento nobiliario. II. El estamento eclesiástico. Madrid.

DOMÍNGUEZ ORTIZ,A. 1973

El Antiguo Régimen: los Reyes Católicos y los Austrias, Madrid.

DOMÍNGUEZ ORTIZ,A. 1984

Política fiscal y cambio social en la España del siglo XVII, Madrid.

DOMÍNGUEZ ORTIZ,A. 1985

Instituciones y sociedad en la España de los Austrias, Barcelona.

FONTANA, J. (ed.) 1982

Comercio y colonias, Madrid.

FONTANA, J. 1955

"Sobre el comercio exterior de Barcelona en la segunda mitad del XVII": Estudios de Historia Moderna 5, pp. 199-219.

GARCÍA FERNÁNDEZ, J. 1953

"Horche (Guadalajara): estudio de estructura agraria": Estudios Geográficos 14, 51, pp. 193-239. 
CRONOLOGÍA Y COYUNTURAS DE LOS MOVIMIENTOS SOCIALES CASTELLANOS, SIGLOS XVI Y XVII

GARCÍA SANZ,A. 1972

Desarrollo y crisis del Antiguo Régimen en Castilla la Vieja: Economía y sociedad en tierras de Segovia, Madrid.

GARCÍA SANZ,A. invierno 1984

"Auge y decadencia en España en los siglos XVI y XVII: economía y sociedad en Castilla": Revista de Historia Económica 1, pp. 2-15.

GÓMEZ URDÁÑEZ,J.L. (dir.) 1986

Cenicero Histórico. Economía y sociedad en una ciudad riojana, Logroño.

GUILARTE,A.M. 1962

El régimen señorial en el siglo $X V I$, Madrid.

GUTIÉRREZ NIETO, J.A. 1973

Las Comunidades como movimiento antiseñorial: La formación del bando realista en la guerra civil castellana de 1520-21, Barcelona.

HALICZER, S. 1987

Los comuneros de Castilla. La forja de una revolución, 1475-1521, Valladolid.

KAMEN, H. 1981

La España de Carlos II, Barcelona.

LARRAZ, J. 1943

La época del mercantilismo en Castilla, Madrid.

LORENZO CADARSO, P.L. 1989

"El conflicto jornalero en Logroño (ss. XVI-XVII)": Berceo 116-117, pp. 81-96.

LORENZO CADARSO, P.L. 1994

"Política económica y rebeldía popular": Gómez Urdáñez, J.L. (coord.), Historia de la Ciudad de Logroño, Logroño, pp. 271-282.

MAURA, duque de, 1954

Vida y reinado de Carlos II, 2 vols., Madrid.

MORENO GARBAYO, N. 1977

Colección de Reales Cédulas del Archivo Histórico Nacional, Madrid.

MOUSNIER, R. 1976

Furores campesinos, Madrid.

MOXO, S. de 1961

"Las desamortizaciones eclesiásticas del siglo XVI": Anuario de Historia del Derecho Español XXXI, Madrid, pp. 327-361.

NADAL, J. 1959

"La revolución de los precios españoles en el siglo XVI. Estado actual de la cuestión": Hispania XIX, 77, pp. 503-529

PALACIO ATARD, V. 1987

España en el siglo XVII. Derrota, agotamiento, decadencia, Madrid ( $1^{\text {a }}$ ed. de 1948).

PÉREZ, J. 1977

La revolución de las Comunidades de Castilla, Madrid.

PORSHNEV, B. 1978

Los levantamientos populares en Francia en el siglo XVII, Madrid. 
PEDRO LUIS LORENZO CADARSO

SALOMÓN, N. 1964

La vida rural castellana en tiempos de Felipe II, Barcelona.

SANZ AYAN, C. 1991

Hacienda y banqueros de Carlos II, Valladolid.

TOMÁS Y VALIENTE, F. 1982

Los validos en la monarquía española del sigo XVII, Madrid.

ULLOA, M. 1963

La Hacienda Real de Castilla en el reinado de Felipe II, Roma

VASSBERG, D. 1983

La venta de tierras baldías; el dominio público y la Corona en Castilla durante el siglo XVI, Madrid.

VASSBERG, D. 1986

Tierra y sociedad en Castilla. Señores, "poderosos" y campesinos en la España del siglo XVI, Barcelona.

VILAR, P. 1974

Crecimiento y desarrollo, Barcelona.

VILAR, P. 1982

Oro y moneda en la Historia, Barcelona.

YAGO, Ch. 1982

"La "crisis de la aristocracia" en la Castilla del XVII": Elliot, J.H. (ed.), Poder y sociedad en la España de los Austrias, Barcelona.

YUN CASALILLA, B. 1985

"Aristocracia, señorío y crecimiento económico en Castilla: algunas reflexiones a partir de los Pimentel y los Enríquez (ss. XVI-XVII)": Revista de Historia Económica, año III, 3, Madrid, pp. 443-471. 